\title{
Are Women Coached by Women More Likely to Become Sport Coaches? Head Coach Gender and Female Collegiate Athletes' Entry into the Coaching Profession
}

\author{
Matea Wasend and Nicole M. LaVoi \\ University of Minnesota
}

\begin{abstract}
A plethora of research on barriers facing women in the coaching profession exists, but less attention has been devoted to female student-athletes' transition into coaching. Some research suggests that female athletes who are coached by women are more likely to become coaches. In the present study, existing research is extended by examining the relationship between collegiate female basketball players' post-playing career behavior and the gender of their collegiate head coach. Two research questions are addressed: (1) Are female collegiate Division-I basketball players who are coached by female head coaches more likely to enter the coaching profession than athletes who are coached by men? And; (2) If female basketball players do enter coaching, are those who were coached by women more likely to persist in coaching? Collegiate head coach gender did not emerge as a significant predictor of athletes' likelihood to enter coaching, but logistic regression indicated that athletes who did enter coaching were 4.1-times more likely to stay in coaching if they had a female head coach. This study extends the scarce and outdated body of research on the potential salience of same-sex coaching role models for female athletes and provides baseline data on collegiate athletes' entry rate into coaching, lending support to advocacy aimed at reversing the current stagnation of women in the sport coaching profession.
\end{abstract}

Keywords: career development, mentorship, role model, social network

Sport participation opportunities have increased dramatically for girls and women in the United States (US) over the past five decades. In a recent update on the state of women in intercollegiate sport in the US, Wilson (2016) reported that participation opportunities for females were at an all-time high in 2016 with well over three million girls competing in high school sports, an increase of more than 1,000 percent since the passage of Title IX in 1972. Women's participation opportunities have also increased yearly at the intercollegiate level; in 2016, 211,886 female athletes competed on National Collegiate Athletic Association (NCAA) intercollegiate teams, compared to about 16,000 in 1970 (Acosta \& Carpenter, 2014). As Schull (2017) notes, increased participation rates would seem to bode well for gender equity in sport coaching. However, despite the increasing athletic capital and experience of girls and women, gender parity in coaching remains elusive (Schull, 2017). In 2017-18, less than half ( 42\%) of US collegiate women's teams were coached by women (LaVoi, 2018), compared to more than $90 \%$ in 1972 (Acosta \& Carpenter, 2014). By contrast, in 2017 close to $96 \%$ of collegiate male teams in the US were coached by men (Wilson, 2016), a number that has remained stable since 1972. Given the prevalence and power of sport in US culture, the underrepresentation of women in coaching (and sport leadership more broadly) means that men hold more power to "communicate who and what is relevant and valued (and who is not)" (LaVoi, 2016b, p. 3). The message being sent to girls and women who grow up with a lack of same-sex role models in coaching positions is no professional place exists for them in athletics, potentially compounding the problem (Rhode \& Walker, 2008).

The authors are with the Tucker Center for Research on Girls \& Women in Sport, University of Minnesota, Minneapolis, MN. LaVoi (nmlavoi@umn.edu) is corresponding author.
As Schull (2017) puts it, female athletes hold "perhaps the most promise to increase women's representation in leadership positions across all levels of sport" (p. 99). Common sense dictates that former athletes are more likely to become coaches than any other population, and the research supports this contention (Gilbert, Côté and Mallet, 2006; Pastore, 1991; Schull, 2017). Yet few researchers have examined the factors that impact student-athletes' (or, specifically, female student-athletes') likelihood to enter coaching-including, perhaps, exposure to same-sex coaching role models.

\section{Literature Review}

\section{Women in Sport Coaching}

The research is clear: women are vastly underrepresented in sport coaching profession across sports, levels, and positions. While over $90 \%$ of US collegiate women's teams were coached by women in 1972, that percentage declined steadily even as Title IX prompted an increase in opportunities and resources in women's sports (Acosta \& Carpenter, 2014). Today, the percentage of US collegiate women's teams coached by female head coaches remains stagnant around $42 \%$ for Division-I and $45 \%$ for Division-III (LaVoi \& Silva-Breen, 2017, 2018); Wilson (2016) reports an even lower $40 \%$ for all NCAA head coaches across all divisions. Meanwhile, just $4.6 \%$ of men's teams are coached by women (Wilson, 2016)). This means that around 23\% of all head coaches of men's and women's collegiate teams are women (Acosta \& Carpenter, 2014). Women are also underrepresented as assistant coaches of both women's and men's teams (Wilson, 2016). Although few studies have addressed the presence of women coaches at the youth and high school sport levels, what research does exist suggests that the representation of female coaches is similar or worse at those levels (LaVoi, 2009). For instance, 
Messner (2009) found that just $19 \%$ of head coach positions in the American Youth Soccer Organization (AYSO) were held by women; in 2017, the Sports \& Fitness Industry Association found that only $23 \%$ of adults who said they had coached youth in the past five years were female (The Aspen Institute, 2018). No comprehensive data exists on the representation of women coaches at the high school level, but a 2014 survey of the Minnesota State High School Coaches Association found that $21.4 \%$ of all high school head coaches were women, with $42 \%$ of girls' teams and $1.9 \%$ of boys teams being led by a female head coach (LaVoi, 2014). Data indicates a scarcity of female coaching role models at all levels of sport.

The persistent underrepresentation of women in coaching remains a frustration to women's sport advocates, especially since women have made strides in many other career sectors-for instance, trade, transportation, and utilities - over the past four decades (United States Bureau of Labor Statistics, 2017). Researchers have demonstrated the lack of women in sport coaching and sport leadership has both arisen from and perpetuated challenges like "blame-the-women" narratives, double standards, homologous reproduction (or the tendency of men to hire men), and the power of the "old boys' club" (LaVoi, 2016a). Recently, women's sport advocate and pioneer, Dr. Carole Ogelsby, stated, "Sport is one of the most gender antagonistic contexts" (personal communication, March 30, 2019). Recently, LaVoi and colleagues (Burton \& LaVoi, 2016; LaVoi, 2016a; LaVoi \& Dutove, 2012) used ecological systems theory to summarize and highlight the many barriers and challenges women coaches face at the individual, interpersonal, organizational, and sociocultural levels within the occupational landscape of sport coaching. For instance, at the individual level, women may demonstrate lower self-efficacy (i.e., belief in their ability to succeed in a given domain) toward coaching than men based on internalized gender stereotypes about sport and leadership; at the interpersonal level, female coaches often face a lack of support from personal networks, especially given prevalent expectations that they fill caregiving roles at home; and at the organizational level, many women coaches report a lack of adequate resources and a lack of organizational support compared to men's teams and male coaches. At every level, these barriers are shaped by a larger sociocultural context that associates sport and leadership with traditional notions of masculinity, values men's sports over women's, and privileges the behaviors of male coaches (Burton \& LaVoi, 2016).

While all of these barriers may negatively impact potential coaches' likelihood to enter the coaching profession, to date, most research on women coaches has focused on quantitatively summarizing their underrepresentation in the sport coaching profession and qualitatively characterizing the many and complex barriers faced by women who have already become coaches. Female athletes - and the factors that might influence them to enter and persist in the coaching profession, such as exposure to salient role models - have received less attention in the research, despite the fact they represent a promising pool of potential future coaches.

\section{Women Coaches as Career Role Models}

Marked increases in female sport participants since the passage of Title IX means that increasing numbers of young women have the athletic capital, experience, knowledge, and passion to become coaches. However, as Bruening, Dixon, Burton, and Madsen (2013) point out, many potential female coaches never enter the profession in the first place. Madsen and McGarry (2016) attribute this in part to persistent gendered social roles that equate sport leadership with masculinity. In interviews with student-athletes at a NCAA Division-I school, they found that females consistently described jobs in college coaching and administration as masculine and viewed them as unrealistic career paths; even those who were interested in pursuing athletic careers felt negatively about their chances of succeeding. Moreover, many female student athletes expressed negative evaluations of female coaches, perhaps reflecting their internalization of traditional gendered social roles.

LaVoi (2016b) proposed that "if girls and young women see females in coaching roles, they will more likely think about coaching as a legitimate and viable career, and so may aspire to become a coach" (p. 4). LaVoi (2016b) is not alone in arguing that increasing female athletes' exposure to female coaches will help break down the stereotype that athletic careers are "masculine" and encourage young women to enter the coaching ranks. Athletic administrators and coaches alike frequently identify increased visibility of and access to female role models in sport-as well as increased coach development opportunities for female athletesas key strategies for increasing the presence of women in sport leadership, including coaching positions (Norman, 2012; Pastore \& Meacci, 1992).

Data exists both outside and within sport to support these calls. Research in domains like education and politics supports the salience of same-sex role models for girls' and women's self-efficacy and realworld achievement outcomes (Beaman, Duflo, Pande, \& Topalova, 2012; Marx \& Roman, 2002; McIntyre, Paulson \& Lord, 2003; Nixon \& Robinson, 1999), and several researchers have found that same-sex role models positively influence women's decisions to work in traditionally male-dominated fields (Green \& Stitt-Gohdes, 1997; Lockwood, 2006). Within sport studies, several researchers have found a positive link between female athletes' exposure to female coaches and their interest and aspirations in the coaching profession. Lirgg, Dibrezzo, and Smith (1994) examined the effect of coach gender on the coaching self-efficacy of female varsity high school basketball players. They found that while coach gender was not significantly correlated with athletes' self-efficacy, it did affect athletes' level of aspiration to coach; athletes coached by women were more likely to say they desired to become a head coach versus an assistant coach than athletes coached by men. Everhart and Chelladurai (1998) similarly examined desire to coach among female and male Division-I collegiate basketball players and found that women with a female coach expressed higher attraction to coaching than those coached by men. Furthermore, the women in the study were more attracted to coaching in general than the male athletes and did not differ from the men in coaching self-efficacy-findings which run counter to the common narrative that women lack the desire or confidence to coach. Female athletes coached by women were also less intimidated by perceived barriers to success in coaching, suggesting they may be potentially more likely to enter the profession.

More recently, Moran-Miller and Flores (2011) replicated and extended Everhart and Chelladurai's research, measuring desire to coach, coaching self-efficacy, coaching valence, perceived hindrances, and role model influence among athletes across four sports and four collegiate divisions. Moran-Miller and Flores found that while the number of female coaches by whom an athlete had been coached over a playing career did not significantly impact interest in coaching or coaching self-efficacy, the perceived quality of the female coaches was positively correlated with interest in coaching and coaching self-efficacy-suggesting that exposure to even just one high-quality female coach may impact athletes' attraction to coaching (2011). Moran-Miller and Flores' conclusion is notable 
because in sports like swimming, soccer, or ice hockey where women coaches are in the minority (LaVoi, 2018), many girls and young women may go through their entire sport career without experiencing a single female coaching role model-but even one high-quality female coach might make a difference on their intentions to coach.

\section{Conceptual Framework}

Bandura's (1977) social cognitive theory informs this study. Social cognitive theory accounts for the interaction between personal factors (such as cognitive ability and emotional responses) and environmental factors (such as role models and social norms) on an individual's self-efficacy, motivation, and behavior. Self-efficacy refers to "people's judgments of their capabilities to organize and execute courses of actions required to attain designated types of performances" (Bandura, 1986, p. 391), and is positively associated with motivation and behavior. Bandura's theory highly emphasizes the importance of models (e.g., coaches) for learning, asserting that individuals learn in large part through observing salient social behavioral models.

Lent, Brown, and Hackett (1994) adapted Bandura's theory to apply specifically to career choices and behaviors, and named this framework social cognitive career theory (SCCT). It centers self-efficacy as one of the most important factors influencing an individual's career aspirations, theorizing that an individual is more likely to be attracted to a certain career if they believe they will be successful (Cunningham \& Singer, 2010). Several studies have linked self-efficacy toward coaching with student athletes' interest in coaching (Everhart \& Chelladurai, 1998; Cunningham, Bruening, Sartore, Sagas, \& Fink, 2005) and assistant coaches' interest in pursuing head coaching positions (Cunningham, Sagas, \& Ashley, 2003), suggesting that SCCT is a useful framework for understanding current or future coaches' occupational intentions.

Social cognitive career theory posits that environmental variables, like exposure to salient role models, can impact self-efficacy towards - and thus likelihood to enter-a certain career (MoranMiller \& Flores, 2011; Quimby \& DeSantis, 2006). Several researchers have found support for this model in the context of sport careers (Cunningham, Bruening, Sartore, Sagas, \& Fink, 2005; Cunningham, 2003; Perrone, Zanardelli, Worthington, \& Chartrand, 2002). For instance, Cunningham, Bruening, Sartore, Sagas, and Fink used SCCT to examine university students' intentions to enter sport careers; among other findings, they found support for the idea that contextual variables (such as the presence of role models) impact likelihood to enter a certain profession through self-efficacy. SCCT is therefore particularly helpful for interrogating how female athletes' exposure to female coaches (i.e., salient role models) might impact their coaching aspirations and coaching behaviors. However, the exact influence of role models-especially same gender role models like female coaches-needs further clarification, particularly within the unique context of sport. While Quimby and DeSantis' (2006) study on women's career choices (not specific to sport) found that role models have a direct influence on career choice, Moran-Miller and Flores' (2011) examination of female athletes found that it was the quality of female role models that positively impacted athletes' self-efficacy toward coaching careers. The SCCT model and existing research support the commonly held belief that coach role models can influence athletes' post-playing career decisions, but a clearer understanding of how female coaches specifically impact female athletes' likelihood to become coaches-rather than just their interest in or self-efficacy toward coaching-could significantly boost efforts to improve the representation of women in coaching.

\section{Research Hypotheses}

Researchers have measured likelihood to enter coaching via coaching self-efficacy, coaching interest, and other aspirational variables; to date, no research has broadened this line of inquiry to include actual career behavior. This study extends existing research by examining US NCAA Division-I collegiate basketball players' early professional careers after graduation and documenting their actual rates of entry into the sport coaching profession. Moreover, it examines the relationship between athletes' entry into coaching and their exposure to salient same-gender career models (female coaches) during their college playing careers, which SCCT and previous research would suggest positively impacts selfefficacy toward coaching and thus likelihood to enter the profession. Based on this theoretical grounding and previous research, the following hypotheses are offered:

Hypothesis 1: Female NCAA Division-I basketball players who are coached by a female head coach are more likely to enter the coaching profession than athletes who are coached by a male head coach.

Hypothesis 2: If female NCAA Division-I collegiate basketball players do enter coaching, those who were coached by a female head coach are more likely to persist in coaching than those who were coached by a male head coach.

\section{Methods}

\section{Study Design}

This exploratory investigation quantitatively examined career behavior of recently graduated NCAA Division-I female collegiate basketball players using digital sources (see Sample). Playing experience (including collegiate head coach gender) and career data were compiled for a sample of female Division-I basketball players who graduated between 2011 and 2015 using Google, online searches of institutional athletics websites, and LinkedIn. Logistic regressions were then used to analyze the relationship between gender of collegiate head coach and entry into coaching, level of coaching, and persistence in coaching at the time of data collection.

Basketball was selected because women comprise around 59\% of head coaches of women's teams at the Division-I level (LaVoi, 2018), which provides a relatively even spread of institutions with male and female head coaches from which to sample. Basketball is also the most popular women's collegiate sport in the US (Irick, 2017). Nearly all NCAA Division-I member institutions (99.4\%) sponsor a women's basketball team, with 350 women's teams and 5,000 athletes competing at the Division-I level (Irick, 2017). Many Division-I basketball programs have entry-level coaching positions (e.g., graduate assistant or director of operations) that are not as prevalent in other women's sports (LaVoi, 2013), suggesting a higher number of opportunities are available for athletes who want to pursue collegiate basketball coaching as a profession compared with other sports. For the purposes of this study, only one sport was examined to control for the potential differences in coaching opportunities across different sports; the NCAA Division-I collegiate level was chosen because it is considered the 
highest collegiate playing level in the US, meaning Division-I graduates are highly marketable as future coaches for all levels of competition.

\section{Sample}

A random sample comprised of 40 NCAA Division-I women's basketball programs was selected out of the population of 350 Division-I women's basketball programs in the US (Irick, 2017). Schools were randomly chosen to account for potential differences in program quality, which could impact athletes' exposure, athletic capital, and marketability as future coaches. Based on exploratory investigations of rosters, 40 was deemed a reasonable number of institutions as it would yield an estimated 250-300 student-athletes, a strong sample size for running non-parametric statistics (Field, 2005).

Institutions were randomly selected, one at a time, from a list of all Division-I schools with women's basketball programs. Online basketball rosters were examined for each randomly selected institution to determine whether the program had one or more female head coaches or one or more male head coaches between 2007 and 2015. Inclusion and exclusion criteria included the following. Schools which had coach turnover from a female head coach to a male head coach or vice versa during that period were excluded to have a consistent sample of athletes who were either coached exclusively by a female head coach (or multiple female head coaches) or exclusively by a male head coach (or multiple male head coaches) between 2007 and 2015. Institutions were eliminated from the sample if they had insufficient online roster data (e.g., no rosters listed prior to 2011). The goal of the sampling was to obtain a relatively even distribution of athletes who were coached by men and coached by women. Once the final sample of institutions $(n=$ 40) was selected, data collection commenced.

\section{Data Collection}

Data was gathered between November 2017 and February 2018. All data gathered is in the public domain; therefore, institutional review board approval was not required.

Women's basketball rosters were examined for eight seasons between 2007-2008 and 2014-2015 at the 40 selected institutions. Inclusion and exclusion criteria for female athletes included the following. Only athletes who played on a team for four consecutive years during that period (graduating between 2011 and 2015) were included in the sample; athletes who transferred in or out of a program or who used a "red-shirt" (a suspension of athletic participation to lengthen eligibility, usually due to injury) to play a fifth year were not included, to control for the potential influence of head coaches from an outside program or spending an extra year in a program. The resulting primary data set included 354 athletes who played for four consecutive collegiate basketball seasons at the same institution, for a male(s) or female(s) coach between 2007 and 2015 .

The following variables were recorded directly from the athletic website rosters for each athlete: institution, athlete name, graduation year, and head coach gender. An effort was then made to find career information for every athlete in the sample $(n=354 ; 192$ coached by women, 161 coached by men) using Google, LinkedIn, Twitter, and/ or Facebook.

If information was found confirming that an athlete entered the coaching profession (i.e., a press release on a collegiate athletics website, an online coaching bio, etc.), the following information was recorded: level of coaching; position; institution or organization; last season coached; whether the athlete currently remains in coaching; and the last year information on the athlete was available (full coding key available on request). If very little or no information was found about an athlete's career path after graduation after repeated online searches, the athlete was excluded from the final sample $(n=117)$. The final sample was comprised of 237 former NCAA Division-I basketball players who graduated between 2011 and 2015. Table 1 shows a descriptive breakdown of the athletes in the final sample by head coach gender and graduation year.

\section{Results}

\section{Data Analysis}

Logistic regression was employed for both research questions. Logistic regression allows for the prediction of a categorical outcome based on continuous or categorical predictor variables, and produces an odds ratio that a certain outcome will occur (entry into coaching, level of coaching, or persistence in coaching) based on an independent variable (gender of head coach). Assumptions, model fit, and practical significance were checked according to Field's (2005) recommendations. Descriptive statistics were also calculated (see Tables 1-4).

The first hypothesis predicted that female collegiate Division-I basketball players who are coached by a female head coach are more likely to enter the coaching profession than athletes who are coached by a male head coach. Descriptive statistics (see Table 2) revealed that 93 of the $237(39.2 \%)$ athletes in the sample entered coaching and $144(60.8 \%)$ did not enter coaching. Out of 142 athletes coached by a female head coach, just over one-third $(n=$ $52,36.6 \%$ ) entered coaching, while a slightly higher percentage of

\section{Table 1 Sample of Female Division-I Basketball Players by Head Coach Gender and Graduation Year}

\begin{tabular}{lccc}
\hline $\begin{array}{l}\text { Graduation } \\
\text { year }\end{array}$ & $\begin{array}{c}\text { Athletes with } \\
\text { female head coach }\end{array}$ & $\begin{array}{c}\text { Athletes with } \\
\text { male head coach }\end{array}$ & $\begin{array}{c}\text { All } \\
\text { athletes }\end{array}$ \\
\hline 2011 & 29 & 17 & 46 \\
2012 & 27 & 19 & 46 \\
2013 & 24 & 22 & 46 \\
2014 & 29 & 20 & 49 \\
2015 & 33 & 17 & 50 \\
Total & 142 & 95 & 237 \\
\hline
\end{tabular}

\section{Table 2 Percentage of Former Female Division-I Basketball Players Who Entered Coaching by Gender of Collegiate Head Coach}

\begin{tabular}{|c|c|c|c|}
\hline & $\begin{array}{l}\text { Athletes with } \\
\text { female head } \\
\text { coach }\end{array}$ & $\begin{array}{l}\text { Athletes with } \\
\text { male head } \\
\text { coach }\end{array}$ & $\begin{array}{c}\text { All } \\
\text { athletes }\end{array}$ \\
\hline & $n(\%)$ & $n(\%)$ & $n(\%)$ \\
\hline \multicolumn{4}{|l|}{$\begin{array}{l}\text { Coaching } \\
\text { career status }\end{array}$} \\
\hline Entered & $52(36.6 \%)$ & $41(43.2 \%)$ & $93(39.2 \%)$ \\
\hline Did not enter & $90(63.4 \%)$ & $54(56.8 \%)$ & $144(60.8 \%)$ \\
\hline Total & 142 & 95 & 237 \\
\hline
\end{tabular}


Table 3 Current Coaching Status of Former Female Division-I Basketball Players Who Entered Coaching by Gender of Collegiate Head Coach

\begin{tabular}{|c|c|c|c|}
\hline & $\begin{array}{c}\text { Athletes with } \\
\text { female head } \\
\text { coach }\end{array}$ & $\begin{array}{l}\text { Athletes with } \\
\text { male head } \\
\text { coach }\end{array}$ & $\begin{array}{c}\text { All } \\
\text { athletes }\end{array}$ \\
\hline & $n(\%)$ & $n(\%)$ & $n(\%)$ \\
\hline \multicolumn{4}{|l|}{ Current coaching status } \\
\hline Currently coaching & $39(75 \%)$ & $20(48.8 \%)$ & $59(63.4 \%)$ \\
\hline Not currently coaching & $8(15.4 \%)$ & $17(41.4 \%)$ & $25(26.9 \%)$ \\
\hline No information & $5(9.6 \%)$ & $4(9.8 \%)$ & $9(9.7 \%)$ \\
\hline Total & 52 & 41 & 93 \\
\hline
\end{tabular}

athletes with a male head coach entered coaching $(n=41,43.2 \%)$. Table 2 summarizes athletes' rate of entry into coaching by gender of collegiate head coach.

To determine whether gender of collegiate head coach significantly predicted athletes' likelihood to enter coaching, logistic regression was employed. Analysis indicated that collegiate head coach gender was not a significant predictor of athletes' entry into coaching. The residual chi-square statistic $\left(\chi^{2}=1.021, p=.312\right)$ was not significant, indicating that head coach gender did not make a significant contribution to the predictive power of the model.

Hypothesis 2 predicted that of female athletes who entered coaching, those who were coached by a female head coach in college are more likely to persist in coaching than those who were coached by a male head coach. Table 3 summarizes the breakdown of athletes' current coaching status by collegiate head coach gender. Data revealed that of all 93 athletes who entered coaching, $59(63.4 \%)$ remained in coaching as of 2017 and $25(26.9 \%)$ were not currently coaching. Out of the 52 athletes who were coached by women, $75 \%(n=39)$ are currently coaching, while a smaller percentage of athletes who were coached by men $(48.8 \%, n=20)$ are currently coaching.

It should be noted that the variable "currently coaching" reflects a range of between two and six years in coaching; athletes who graduated in 2011 who are "currently coaching" have been coaching for six years, while athletes who graduated in 2015 who are "currently coaching" have been coaching for two years. Table 4 includes the full distribution of athletes' current coaching status by their year of graduation, for the 93 athletes who entered coaching.
Athletes who were coached by women are "currently coaching" at a higher rate than athletes who were coached by men for every graduation year.

Logistic regression was utilized to determine whether gender of collegiate head coach was a significant predictor of athletes' current coaching status. Nine athletes were excluded from the sample for this analysis because no information was available to indicate whether they remained in coaching as of 2017, meaning the regression was run from a sample of 84 athletes who entered coaching after graduating. Logistic regression analysis revealed significant omnibus goodness of fit for current coaching status; the residual chi-square statistic $\left(\chi^{2}=8.35, p<.004\right)$ was significant. Further examination indicates that the odds $(\exp b)$ that an athlete who was coached by a woman in college is still coaching are 4.1-times higher than the odds that an athlete who was coached by a man is still coaching. The $95 \%$ confidence interval for exp $b$ was 1.527 (lower) and 11.245 (upper).

Logistic regression was also utilized to determine whether the year in which athletes graduated significantly predicted whether they remained in coaching as of 2017, since the distribution of athletes' graduation years was unequal for female head coaches and male head coaches-which may have impacted the results of the logistic regression. However, graduation year did not emerge as a significant predictor of whether an athlete remained in coaching; the residual chi-square statistic $(p=.789)$ was not significant, indicating that graduation year did not make a significant contribution to the predictive power of the model.

\section{Discussion}

SCCT suggests that athletes who are exposed to salient coaching models (in this case, same-gender head coaches) will have higher self-efficacy toward coaching, and thus be more likely to enter the profession. Moreover, some previous research has indicated that female athletes who are coached by women may be more likely to enter the coaching profession (Everhart \& Chelladurai, 1998; Lirgg et al., 1994) or coach at a high level (Lirgg et al., 1994). However, these hypotheses were not supported by the data in this study. Head coach gender was not a significant predictor of athletes' likelihood to enter coaching or the level at which they most recently coached. In fact, compared to athletes who were coached by women, a higher percentage of athletes coached by male head coaches entered the coaching profession, although the difference was not statistically significant. Similarly, the descriptive statistics demonstrated that a

Table 4 Current Coaching Status of Former Female Division-I Basketball Players by Graduation Year and Gender of Collegiate Head Coach

\begin{tabular}{|c|c|c|c|c|c|c|}
\hline \multirow{3}{*}{$\begin{array}{l}\text { Collegiate Head } \\
\text { Coach Gender }\end{array}$} & \multicolumn{6}{|c|}{ Current coaching status } \\
\hline & \multicolumn{2}{|c|}{ Currently coaching } & \multicolumn{2}{|c|}{ Not currently coaching } & \multicolumn{2}{|c|}{ No information } \\
\hline & Male $n(\%)$ & Female $n(\%)$ & Male $n(\%)$ & Female $n(\%)$ & Male $n(\%)$ & Female $n(\%)$ \\
\hline \multicolumn{7}{|l|}{ Graduation year } \\
\hline 2011 & $3(30 \%)$ & $7(70 \%)$ & $7(70 \%)$ & $2(20 \%)$ & $0(0 \%)$ & $1(10 \%)$ \\
\hline 2012 & $5(71.4 \%)$ & $10(90.9 \%)$ & $2(28.6 \%)$ & $1(9.1 \%)$ & $0(0 \%)$ & $0(0 \%)$ \\
\hline 2013 & $3(37.5 \%)$ & $6(54.5 \%)$ & $3(37.5 \%)$ & $3(27.3 \%)$ & $2(25 \%)$ & $2(18.2 \%)$ \\
\hline 2014 & $5(50 \%)$ & $6(85.7 \%)$ & $3(30 \%)$ & $1(14.3 \%)$ & $2(20 \%)$ & $0(0 \%)$ \\
\hline 2015 & $4(66.6 \%)$ & $10(76.9 \%)$ & $2(33.3 \%)$ & $1(7.7 \%)$ & $0(0 \%)$ & $2(15.4 \%)$ \\
\hline Total & $20(48.8 \%)$ & $39(75 \%)$ & $17(41.4 \%)$ & $8(15.4 \%)$ & $4(9.8 \%)$ & $5(9.6 \%)$ \\
\hline
\end{tabular}


higher percentage of athletes who were coached by men most recently coached at college level $(63.4 \%)$ compared to athletes who were coached by women $(46.2 \%)$, although this difference also lacked statistical significance.

On one hand, these findings may suggest that athletes' exposure to same-gender coaching models did not positively impact their self-efficacy toward coaching, which SCCT posits is a prerequisite to entering and persisting in a profession. However, this study did not measure self-efficacy or other quantitative variables as previous research did, so that is not a foregone conclusion. It is also possible that these findings point to a gap between athletes' intentions or interest in coaching as expressed in a survey and their reallife early career behaviors. It is possible that female athletes who are coached by women $d o$ have greater self-efficacy toward coaching (as suggested by SCCT), express greater attraction to coaching (Everhart \& Chelladurai, 1998), or aspire to coach at a higher level (Lirgg et al., 1994) than those coached by men, but that external factors at the interpersonal, organizational, or sociocultural level more strongly impact whether they enter the coaching profession.

It is also quite possible that mere exposure to female coaches does not by default positively impact female athletes' self-efficacy toward coaching, especially given persistent negative attitudes towards women coaches held by many athletes. Instead it may be that the quality of athletes' relationships with their coaches is what engenders a "role model effect", which aligns with MoranMiller and Flores' (2011) conclusion that those athletes who had high-quality relationships with their female coaches demonstrated higher self-efficacy toward and interest in coaching. Madsen and McGarry (2016) argue that active mentoring of female athletes into coaching careers - by coaches of either gender-is more likely to lead female athletes to become coaches than mere exposure to female coaches. Social cognitive theory would support this conclusion, as Bandura (1977, 1986) posits that models must be relatable to observers to be effective. While gender is a potentially salient point of similarity with which athletes might connect, athletes' likelihood to enter coaching (especially at the college level) may be more strongly impacted by their relationships with their coaches, their overall collegiate experience, their attitudes toward their sport, their self-efficacy in their sport, or other factors; SCCT suggests that career choice is influenced by a variety of personal and environmental factors that could not all be captured in the present study. Moreover, as Cunningham, Bruening, Sartore, Sagas, and Fink (2005) point out in their study of college students' interest in sport professions, interest in sport careers may not necessarily lead students to enter into said careers without outside support from counselors or professors (or in this case, coaches). Future studies should replicate and extend the efforts of Lirgg et al. (1994), Everhart and Chelladurai (1998), and Moran-Miller and Flores (2011) combining qualitative and quantitative data to clarify the factors that influence athletes' likelihood to enter coaching, including but not limited to the role of coach gender. A better understanding of these factors will strengthen advocacy initiatives for increasing the representation of women in sport coaching.

The finding that more athletes with male head coaches entered coaching - although the difference from those with female coaches was not statistically significant-may also point to the structural advantages held by male coaches, which are likely to positively impact their players who aspire to coach. Katz, Walker, and Hindman (2018) compared the informal networks of Senior Women Administrators (SWAs) and male athletic directors (ADs) and found that the women's network is less robust than the male network, confirming the existence of the of-cited "old boys' club", which they argue may contribute to the lack of women in positions of sport leadership. Additionally researchers who studied the social network connectivity of ADs, SWAs and head coaches in NCAA D-I athletics indicated that while the average female coach is better connected to athletic leadership than the average male coach across all indicators (network size, network density, position in the network), women do not have better outcomes in the job market (Walker, Katz, \& LaVoi, 2019). Findings of both aforementioned network studies point to institutionalized access discrimination that privilege men. Although this study focused on individual level factors impacting athletes' likelihood to coach, based on other data, organizational level factors are likely strongly at play. Female athletes who are interested in coaching may be positively or negatively impacted by the institutionalized network connections held by their coaches, with male coaches being more likely to be linked to strong, powerful cohesive, and robust professional networks.

Collegiate head coach gender did emerge as a significant predictor of whether athletes were still coaching at the time of data collection. This is a somewhat curious finding, given the finding that head coach gender did not influence athletes' likelihood to enter coaching in the first place. This finding may point to Everhart and Chelladurai's (1998) conclusion that women coached by female coaches were less intimidated by perceived discrimination, a real barrier faced by many women in the coaching profession. Everhart and Chelladurai speculate that female athletes who have observed female coach role models overcome discrimination may be more likely to feel they could similarly surmount unequal treatment in their own career. It is possible that for the female athletes in this sample, their female collegiate coaches acted as retroactive buffers against perceived barriers to success in coaching. Research by Dixon and Bruening (2007) also suggests that women coaches may model effective ways to balance professional life with family obligations like domestic labor and childcare, which continue to disproportionately burden women. Bruening and Dixon (2007) documented many coping mechanisms employed by female coaches experiencing work-family conflict, some of which female athletes aspiring to coach may pick up on for use in their own careers. Indeed, several coaches in the Bruening and Dixon study noted that athletes reacted positively to their coaches' work-family conflict after they graduated and reflected on their experiences "witnessing firsthand how balancing work and family was possible" (p. 477). This study's finding that female athletes coached by women were more likely to persist in coaching suggests that women coaches may be modeling effective ways to deal with work-family conflict for their athletes who do become coaches down the road, and may provide active mentoring and social support for them when entering and staying in coaching.

Given that the athletes in this study could be coaching for a maximum of two to six years, however, future research should determine whether collegiate head coach gender is a significant predictor of athletes' persistence in coaching over a longer period of time (perhaps defining "persistence" as five years or more) in addition to other sports and levels. Qualitative investigations could also help clarify the nature of this relationship.

This study is the first of its kind to track the percentage of female collegiate athletes who become coaches after graduation. Descriptive statistics demonstrated that nearly $40 \%$ of athletes in the sample entered the coaching profession as either part-time or full-time coaches at the youth, high school, or college level after they graduated. These numbers help to refute the common narrative that "women are not interested in coaching"; clearly, if well over one-third of female Division-I collegiate basketball players enter the profession (however briefly) after graduating, they are 
interested in coaching. While this finding is not generalizable to all female athletes, it provides an unprecedented baseline to which data on female athletes' entry into coaching in other sports and across competitive levels could be compared. Perhaps more importantly, this data could be compared to the entry rates of male athletes to help clarify whether the shortage of female coaches stems from fewer female athletes entering coaching or more early career female coaches leaving coaching after they have entered.

\section{Limitations}

This study has several methodological limitations. For one, it relies on information found on the internet, which could be inaccurate or incomplete. Rosters may be wrong, as could information about athletes' career behaviors. Athletes may have changed their names since graduating, as was discovered in several cases. It is highly possible that information about former athletes coaching at the youth or high school level is not available online, which may impact the accuracy of the results. However, using the internet is a reasonable starting point and method of quickly tracking the career behavior of hundreds of athletes. The sample size was also relatively small and all participants were from the same sport and same NCAA level of competition, limiting generalizability to other sports, competitive levels, and coaching landscapes outside the US. This study also only accounts for gender of athletes' college head coaches; it is highly likely that athletes' outlook on the coaching profession is impacted by their early playing experiences, possibly including exposure to female coaches in youth or high school sport. Athletes' relationships with their assistant coaches, who are also role models, may also be a salient factor.

\section{Future Research}

Despite the logical progression from playing collegiately to coaching, relatively little research has examined the factors that influence athletes' likelihood to enter coaching or the early career behaviors of new coaches, and these studies have been largely qualitative in nature (Lirgg et al., 1994; Everhart \& Chelladurai, 1998; Moran-Miller \& Flores, 2011; Madsen \& McGarry, 2016). Future studies should replicate the research questions examined here across different sports and playing levels. Researchers could examine a larger sample of athletes from a single graduation year, and observe athletes over a longer period of time, to more clearly track the career trajectories of athletes who were coached by men versus women Perhaps more critically, a similar methodology could be used in other useful ways. For instance, researchers could compare early career behaviors of female athletes to those of male athletes to help clarify whether women are underrepresented in coaching because they do not enter at the same rate as men or because they leave the profession earlier, which could help advocates strengthen and plug the leaky coaching "pipeline" by more strategically directing resources and support.

Future research should also seek a clearer understanding of the many factors that influence a collegiate athlete's likelihood to enter coaching beyond head coach gender. Qualitative or mixedmethods designs could take a broader view of SCCT, factoring in the quality of an athlete's relationship with their head or assistant coaches, their exposure to different coach influences in pre-college playing years, their perceived playing and coaching ability, their perceptions about their collegiate playing experience, deliberate mentoring behaviors from their head or assistant coaches, and other qualitative measures alongside the type of quantitative gathered in this study, to provide a more complete picture of why female athletes enter the coaching profession. Future research could also examine the organizational factors that may impact athletes' interest in and likelihood to enter coaching, such as the network connections of their head coaches as noted in the previous section. Researchers could partner with coaching associations to recruit female coaches as participants in such projects.

Finally, more research on coaches' early career behaviors would strengthen understanding of the female coaching pipeline and enable more targeted advocacy. Future studies could use the methodology piloted here to closely examine progression through positions and departure from coaching. If such numerical data were to indicate that female coaches are most likely to quit within a certain time frame after entering the profession, advocates could better target supports to coaches who need them most. This type of career-tracking study could be sustained longitudinally in the style of Acosta and Carpenter's (2014) reports on women in sport leadership or LaVoi's (2018) Women in College Coaching Report Cards to provide a measure of progress toward gender equity in the coaching profession.

\section{Conclusion}

While US women have made considerable and unprecedented gains in sport participation since the passage of Title IX in 1972, they remain underrepresented in athletic leadership (Acosta \& Carpenter, 2014; LaVoi, 2018). Over the past few decades, research has clarified the many barriers facing existing coaches (LaVoi, 2016a), but less attention has been paid to the most likely pool of potential female coaches: female athletes. This study builds on social cognitive career theory and limited existing research to examine whether the gender of female athletes' collegiate head coach is correlated with their likelihood to enter coaching and their persistence in the coaching profession in the early years of their career. While the data in this study indicated no significant relationship between an athlete's collegiate head coach gender and their likelihood to enter coaching, it does determine that female athletes who are coached by women are four times more likely to persist in the coaching profession in the first two to six years of their coaching careers than athletes who are coached by men. This suggests that female coaches may help to sustain female athletes' early coaching careers. Combined with recent quantitative data which specified that gender of the coach is not a significant determinant of team performance in women's soccer leagues (Gomez-Gonzalez, Dietl, \& Nesseler, 2018), both data are powerful indicators for athletic administrators to hire and support female coaches.

The data herein also offers hard proof that female athletes are interested in coaching. Nearly $40 \%$ of the collegiate basketball players in this sample sustained involvement with their sport by becoming coaches after graduation and contests lingering claims that "women do not want to coach". However, given the persistent underrepresentation of women in coaching, the female coaching pipeline is clearly leaky and failing women somewhere along their career trajectory. Researchers must turn their attention to the influences on collegiate athletes' entry into and persistence in coaching to better support the promising contingent of early career female coaches.

\section{References}

Acosta, R.V., \& Carpenter, L.J. (2014). Women in intercollegiate sport: A longitudinal, national study thirty-seven-year update. Retrieved from http://webpages.charter.net/womeninsport 
Bandura, A. (1977). Self-efficacy: Toward a unifying theory of behavioral change. Psychological Review, 84, 191-215. PubMed ID: 847061. doi:10.1037/0033-295X.84.2.191

Bandura, A. (1986). Social foundations of thought and action: A social cognitive theory. Englewood Cliffs, NJ: Prentice-Hall.

Beaman, L., Duflo, E., Pande, R., \& Topalova, P. (2012). Female leadership raises aspirations and educational attainment for girls: A policy experiment in India. Science, 335(6068), 582-586. PubMed ID: 22245740. doi:10.1126/science. 1212382

Bruening, J.E., \& Dixon, M.A. (2007). Work-family conflict in coaching II: Managing role conflict. Journal of Sport Management, 21, 471-496. doi:10.1123/jsm.21.4.471

Bruening, J.E., Dixon, M.A., Burton, L.J., \& Madsen, R.M. (2013). Women in coaching: The work-life interface. In P. Potrac, W. Gilbert \& J. Denison (Eds.), Routledge handbook of sports coaching (pp. 411-423). London, UK: Routledge.

Burton, L.J., \& LaVoi, N.M. (2016). An ecological/multisystem approach to understanding and examining women coaches. In N.M. LaVoi (Ed.), Women in Sports Coaching (pp. 49-62). New York, NY: Routledge.

Cunningham, G.B. (2003). Already aware of the glass ceiling: Racerelated effects of perceived opportunity on the career choices of college athletes. Journal of African American Studies, 7(1), 57-71. doi:10.1007/s12111-003-1003-8

Cunningham, G.B., Bruening, J., Sartore, M.L., Sagas, M., \& Fink, J.S. (2005). The application of Social Cognitive Career Theory to sport and leisure career choices. Journal of Career Development, 32(2), 122-138. doi:10.1177/0894845305279164

Cunningham, G.B., Sagas, M., \& Ashley, F.B. (2003). Coaching self-efficacy, desire to become a head coach, and occupational turnover intent: Gender differences between NCAA assistant coaches of women's teams. International Journal of Sport Psychology, 34, 125-137.

Cunningham, G.B., \& Singer, J.N. (2010). "You'll face discrimination wherever you go": Student athletes' intentions to enter the coaching profession. Journal of Applied Social Psychology, 40(7), 1708-1727. doi:10.1111/j.1559-1816.2010.00636.x

Dixon, M.A., \& Bruening, J.E. (2007). Work-family conflict in coaching I: A top-down perspective. Journal of Sport Management, 21, 377-406. doi:10.1123/jsm.21.3.377

Everhart, C.B., \& Chelladurai, P. (1998). Gender differences in preferences for coaching as an occupation: The role of self-efficacy, valence, and perceived barriers. Research Quarterly for Exercise and Sport, 69(2), 188-200. PubMed ID: 9635332. doi:10.1080/ 02701367.1998 .10607683

Field, A. (2005). Discovering statistics using SPSS (2nd ed.). Thousand Oaks, CA: Sage Publications.

Gilbert, W., Côté, J., \& Mallett, C. (2006). Developmental paths and activities of successful sport coaches. International Journal of Sports Science \& Coaching, 1(1), 69-76. doi:10.1260/174795406776338526

Gomez-Gonzalez, C., Dietl, H., \& Nesseler, C. (2018). Does performance justify the underrepresentation of women coaches? Evidence from professional women's soccer. Sport Management Review. Advance online publication. doi:10.1016/j.smr.2018.09.008

Greene, C.K., \& Stitt-Gohdes, W.L. (1997). Factors that influence women's choices to work in the trades. Journal of Career Development, 23(4), 265-278. doi:10.1007/BF02359211

Irick, E. (2017). Student-athlete participation: 1981-82- 2016-17. Retrieved from http://www.ncaa.org/sites/default/files/2016-17NCAA0472_ParticRatesReport-FINAL_20171120.pdf

Katz, M., Walker, N.A., \& Hindman, L.C. (2018). Gendered leadership networks in the NCAA: Analyzing affiliation networks of senior woman administrators and athletic directors. Journal of Sport Management, 32(2), 135-149. doi:10.1123/jsm.2017-0306
LaVoi, N.M. (2009). Occupational sex segregation in a youth soccer organization: Females in positions of power. Women in Sport and Physical Activity Journal, 18(2), 25-37. doi:10.1123/wspaj.18. 2.25

LaVoi, N.M. (2013). The decline of women coaches in collegiate athletics: A report on select NCAA Division-I FBS institutions, 2012-13. Minneapolis, MN: The Tucker Center for Research on Girls \& Women in Sport.

LaVoi, N.M. (2014). Minnesota State High School Coaches Association report 2013-2014. Minneapolis, MN: Tucker Center for Research on Girls \& Women in Sport.

LaVoi, N.M. (2016a). A framework to understand experiences of women coaches around the globe: The Ecological-Intersectional Model. In N.M. LaVoi (Ed.), Women in Sports Coaching (pp. 13-34). New York, NY: Routledge.

LaVoi, N.M. (Ed.). (2016b). Women in Sports Coaching. New York, NY: Routledge.

LaVoi, N.M. (2018). Head coaches of women's collegiate teams: A report on seven select NCAA Division-I conferences, 2017-2018. Minneapolis, MN: The Tucker Center for Research on Girls \& Women in Sport.

LaVoi, N.M., \& Dutove, J.K. (2012). Barriers and supports for female coaches: An ecological model. Sports Coaching Review, 1(1), $17-37$.

LaVoi, N.M., \& Silva-Breen, H. (2017, December). Head coaches of women's collegiate teams: A comprehensive report on NCAA Division-III institutions, 2017-18. Minneapolis, MN: The Tucker Center for Research on Girls \& Women in Sport.

LaVoi, N.M., \& Silva-Breen, H. (2018, July). Head coaches of women's collegiate teams: A comprehensive report on NCAA Division-I institutions, 2017-18. Minneapolis, MN: The Tucker Center for Research on Girls \& Women in Sport.

Lent, R.W., Brown, S.D., \& Hackett, G. (1994). Toward a unifying social cognitive career theory of career and academic interest, choice, and performance. Journal of Vocational Behavior, 45, 79-122. doi:10. 1006/jvbe.1994.1027

Lirgg, C.D., Dibrezzo, R., \& Smith, A.N. (1994). Influence of gender of coach on perceptions of basketball and coaching self-efficacy and aspirations of high school female basketball players. Women in Sport \& Physical Activity Journal, 3(1), 1-14. doi:10.1123/wspaj.3.1.1

Lockwood, P. (2006). "Someone like me can be successful": Do college students need same-gender role models? Psychology of Women Quarterly, 30(1), 36-46. doi:10.1111/j.1471-6402.2006.00260.x

Madsen, R.M., \& McGarry, J.E. (2016). "Dads play basketball, moms go shopping!" Social role theory and the preference for female coaches. Journal of Contemporary Athletics, 10(4), 277-284.

Marx, D.M., \& Roman, J.S. (2002). Female role models: Protecting women's math test performance. Personality and Social Psychology Bulletin, 28(9), 1183-1193. doi:10.1177/01461672022812004

McIntyre, R.B., Paulson, R.M., \& Lord, C.G. (2003). Alleviating women's mathematics stereotype threat through salience of group achievements. Journal of Experimental Social Psychology, 39(1), 83-90. doi:10.1016/S0022-1031(02)00513-9

Messner, M.A. (2009). It's all for the kids: Gender, families, and youth sports. Los Angeles, CA: University of California Press.

Moran-Miller, K., \& Flores, L.Y. (2011). Where are the women in women's sports? Predictors of female athletes' interest in a coaching career. Research Quarterly for Exercise and Sport, 82(1), 109-117. PubMed ID: 21462691. doi:10.1080/02701367.2011.10599727

Nixon, L.A., \& Robinson, M.D. (1999). The educational attainment of young women: Role model effects of female high school faculty. Demography, 36(2), 185. PubMed ID: 10332610. doi:10.2307/ 2648107 
Norman, L. (2012). Developing female coaches: Strategies from women themselves. Asia-Pacific Journal of Health, Sport and Physical Education, 3(3), 227-238. doi:10.1080/18377122.2012.721725

Pastore, D.L. (1991). Male and female coaches of women's athletic teams: Reasons for entering and leaving the profession. Journal of Sport Management, 5, 128-143. doi:10.1123/jsm.5.2.128

Pastore, D.L., \& Meacci, W.G. (1992). Administrative recommendations for increasing the number of female coaches at two-year colleges. Physical Educator, 49(2), 67.

Perrone, K.M., Zanardelli, G., Worthington, E.L., Jr., \& Chartrand, J.M. (2002). Role model influence on career decidedness. College Student Journal, 36(1), 109-112.

Quimby, J., \& DeSantis, A. (2006). The influence of role models on women's career choices. The Career Development Quarterly, 54, 297-306. doi:10.1002/j.2161-0045.2006.tb00195.x

Rhode, D.L., \& Walker, C.J. (2008). Gender equity in college athletics: Women coaches as a case study. Stanford Journal of Civil Rights \& Civil Liberties, 4, 1-49.
Schull, V.D. (2017). Young women in sport: understanding leadership in sport. In L.J. Burton \& S. Leberman (Eds.), Women in Sport Leadership: Research and Practice for Change (pp. 98-115). New York, NY: Routledge.

The Aspen Institute. (2018). State of play 2018: Trends and developments. Retrieved from https://www.aspeninstitute.org/publications/state-ofplay-2018-trends-and-developments/

U.S. Bureau of Labor Statistics. (2017). Women at Work. Retrieved from https://www.bls.gov/spotlight/2017/women-at-work/pdf/women-atwork.pdf

Walker, N., Katz, M., \& LaVoi, N.M. (2019). Gendered hiring networks and access discrimination: A social network analysis of leadership positions in NCAA sports. Proceedings from North American Society for Sport Management Conference. Champaign, IL: Human Kinetics.

Wilson, A.S. (2016). 45 years of Title IX: The status of women in intercollegiate athletics. Retrieved from http://www.ncaa.org/sites/ default/files/TitleIX45-295-FINAL_WEB.pdf 